\title{
UNA PINTURA DESCONOCIDA DE LA PLAZA MAYOR DE MEXICO
}

\author{
P O R \\ JUSTINO F ER N A N D Z \\ A Manuel Romero de Terreros
} A ta serie de pinturas conocidas de la Plaza Mayor de la ciudad de Mé-
xico, hay que agregar una más, de no escaso mérito e interés, tanto por su calidad artística como por ser su autor el general francés Conde Octaviano D'Alvimar.

Debo a la bondad de mi éstimado amigo el general Juan Manuel Torrea, la noticia de la existencia, en una colección privada en Londres, de la pintura en que me ocupo y para cuya reproducción he obtenido el respectivo permiso, que agradezco.

El nombre de Octaviano D'Alvimar no nos era desconocido, ya que bastante ruido hizo en el país $y$ ftrera de el, a principios del siglo $x I x$, con motivo de sus extrańas actividades subversivas, que le valieron ser expulsado de México por dos veces.

No sería posible que con motivo de la presente nota nos extendiéramos a considerar en detalle la biografía de D'Alvimar, rica en aventuras y 
Jeyendas, al parecer; por el contrario, valgan más bien estas noticias como una aportación a aquélla, a la vez que a la historia del arte en México.

Hace tiempo, bajo el título de "El aventurero conde Octaviano d'A1vimar. Espía de Napoleón”, aparecieron publicađos varios documentos en el Boletin del Archivo General de la Nación. (T. vir. No 2., 1936.) Los anteceden dos textos: uno de don Carlos Maria de Bustamante, perteneciente al Suplemento de la Historia de los tres siglos de México, etc., y otra noticia tomada de México a través de los siglos. (T. Iv. México independiente.) 1 Por todo lo anterior quedamos enterados, a lo menos, de las circunstancias de las dos visitas que hizo D'Alvimar a nuestro país, de sus dos expulsiones $y$ de algunos de sus antecedentes.

Por primera vez aparece $D^{\prime}$ Alvimar detenido en Nacodoches, el 5 de agosto de 1808; llevaba pasaporte francés para ir a los Estados Únidos y según propia declaración, por orden de su amo Napoleón debía pasar a México para obrar conforme a instrucciones del Marqués de San Sirnón, que suponia hallarse ocupando el cargo de Virrey. El Acuerdo resolvió encerrarlo en el castillo de Perote, como prisionero de guerra, a menos de que los papeles que se hallasen en su poder demandasen tomar otra providencia. Por ellos se enteraron de que D'Alvimar había venido en la expedición de l'Clere (sic) a Santo Domingo; que este jefe lo comisionó en junio de 1802 para que pasase a Caracas, Cartagena y Santa Fe, en solicitud de auxilios de toda especie para su ejército; que trató con los magistrados de aquellas provincias $y$, finalmente, que estuvo en La Habana y que era pariente de Napoleón. El Virrey dijo a la junta que aun cuando esto último no fuese positivo, sí lo era que D'Alvimar era un confidente y espía de Bonaparte.

En camino a México, como prisionero, se detuvo en Monclova y a pesar de que había dado su palabra de honor de mantenerse como tal, intentó fugarse, pero fué reaprehendido y se le privó de sus armas y objetos personales. Entonces escribió al Virrey suplićńndole remitiese a su destino cuatro cartas, una de ellas dirigida a Napoleón, avisándole de su circunstancia. Trasladado a Veracruz, el gobernador de aquella plaza le retiró el dinero que llevaba consigo y un cofrecillo de alhajas y se le internó en el castillo de San Juan de Ulúa, el 27 de enero de 1809 , donde se le trató con dureza. Por último, cuando la Regencia envió orden de

1 Véase también la Historia de Méjico de Lucas Alamán y el artículo de Rafael Heliodoro Valle en Excélsior, de septiembre 8 de 1947, titulado: "Napoleón, conspirador en México". 
que se le juzgase, ya se le habia embarcado para Europa en un buque inglés, pues dijeron que corría riesgo su vida si se le hubiese enviado en un navío español.

En el año de 1822 reaparece en México D'Alvimar, tratando de recuperar su equipaje y procurando insintuarse en el ánimo de Iturbide, pidiéndole que lo hiciese teniente general del ejército mexicano. Don Carlos Maria de Bustamante lo conoció y dice de él: "que era un hombre muy servil en sus opiniones políticas y tanto, que osó publicar un papelucho por la prensa, en francés con voces castellanas (como no pocos se publican hoy, pues se va perdiendo el idioma lastimosamente), impugnando la libertad de imprenta. Como diputado que yo era entonces al Congreso General, me hizo varias visitas en $\mathrm{mi}$ casa, y pude conocer que era el hombre más propio para llevar a efecto un gobierno militar y bárbaro, y que Napoleón no se equivocó en elegirlo por satélite suyo".

Por la filiación certificada (28 de octubre de 1823) que aparece entre los documentos de su proceso, podemos tener idea de su físico: tenía entonces cincuenta y cuatro años de edad, ojos azules, barba escasa, nariz abultada, pelo güero entrecano, estatuta regular, orejas agujereadas para zarcillos (se dice que había estado en oriente en un harem, disfrazado de odalisca) y diez lunares en la cara.

En la noticia de Mésico a travós de los siglos, se asienta que: "A mediados de septiembre (1823), estalló en San Miguel el Grande una revolución a causa de haber atacado esa villa una numerosa partida de ladrones, que, perseguidos, fueron apresados algunos, y entre ellos uno llamado Azpericueta y un francés D'Alvimar..." Una vez preso el inquieto aventurero, se tomaron todo género de precauciones para evitar cualquier intento de fuga, quedando asegurado y sin comunicación en el cuartel del regimiento de infantería N\$ 3 , en la ciudad de México.

El 21 de octubre de 1823, el licenciado don Agustín Pérez de Lebrija, Juez de Letras de la capital, pronunció su sentencia sobre el caso, declarando que: "por haber tratado de distraer o separar la provincia de Guanajuato y demás que se adhieran a ésta, de la obediencia al Soberano Congreso y Stupremo Poder Ejecutivo, formando al efecto nuevo plan de revolución, como lo es el que en la causa corre agregado bajo la firma del expresado D'Alvimar; la declaración dada por éste en que confiesa ser suyo el citado plan y haberlo formado y emitido a la Junta de Celaya con la mira de ser aprobado por ésta ... Fallo deba condenar y condeno al indicado don Octaviano D'Alvimar a destierro perpetuo de esta Amé- 
rica, remitiéndose por cordillera al puerto que señale el Supremo Gobierno ...."

D'Alvimar no quedó conforme, claro está, con la anterior sentencia y apeló por escrito al Marqués de Vivanco, Capitán General de México (octubre 30, 1823), en contra "de la infame decisión del prevaricador Lebrija ... que no habla sino el idioma del infierno en la boca del demonio...", declarándose inocente y suplicándole "se sirva reflexionar que estoy acá con mi sentencia del Gobierno español, que me dice que reclame respecto de los quinientos cuarenta y ocho mil pesos que me embargaron cwando por parte del rey José, uenia a reemplasar a Iturrigaray. Nacida rico, y arruinado por segunda voz por esta tierra, no me sonrojo de mi noble pobreza; pero a la verdad hablo con mi corazón en la mano, diciendo a V. E. que cuando salf últimamente de Francia, por habor muerto mi padre en el mismo cadalso que Luis XVI, permitió el rey actual que mi respetable madre (cuyos bienes se confiscaron entonces), recibieso mi corto sueldo durante mi ausencia ..." por último, pedia que se le dejase libre en el interior del edificio, que era el antiguo convento de Betlemitas.

En una segunda carta igualmente dirigida al Marqués de Vivanco (noviembre 3 de 1823), se quejaba de que "a lo claro que cada uno the está robando a quien mejor. Ya me habia estafado el juex Lebrija lo que se le antojó coger por los coutos de su pretendida causa ... no puedo tampoco obrar como si fuese rico, en el momento por cierto más critico de mi vida en cuanto a lo que tiende a dinero, pues estoy al punto de verme expuesto a mil males fuera de mi patria". No obstante sus quejas y lamentaciones, el 7 de noviembre se dió orden de que D'Alvimar fuese conducido al puerto de Veracruz, para ser embarcado en Alvarado, con destino al lugar que él mismo eliglese, teniendo que pagar sus propios gastos y los costos de su juicio y llevando en depósito el dinero restante el comandante de la partida del regimiento de caballería núm. 4, don Joaquín Islas, quien debería conducirlo, para entregárselo en el momento de partir. Por precaución se participó el asunto a todos los comandantes de los puertos "para que impidan el desambarque de este individuo si intenta regresar". Todavia tres años más adelante, en mayo de 1826 , el Secretario de Relaciones de los Estados Unidos Mexicanos, comunicaba a la legación mexicana en Londres que hiciese publicar en los diarios de Europa el decreto de expulsión del general D'Alvimar. (Archivo Gral. de la $\mathrm{S}$. de R. E: Exp. 9.4-1.) 
Todo lo anterior da buena idea de las andanzas de D'Alvimar en nuestro país y de sus fallidas intenciones, pero aún hay más. Gracias a la bondad del general Juan Manuel Torrea, director del Archivo General de la Secretaría de Relaciones Exteriores, reproduzco aquí, como apéndice a esta nota, una interesante carta ológrafa de D'Alvimar, que se conserva en el expediente relativo a su expulsión (Exp. 9-4-1), en aquel archivo. Ella nos remite más concretamente a mi objeto, o sea, a la pintura de la Plaza Mayor de México a que he de referirme. La carta en cuestión está dirigida a don Agustín de Iturbide, el 20 de septiembre de 1822, es decir, un año antes de los sucesos ocurridos en San Miguel el Grande, que culminaron con la aprehensión de D'Alvimar, como se ha dicho. No cabe duda que por los antecedentes del aventurero francés, ya con anterioridad estaba decidida su expulsión del país, pues su carta principia con el siguiente párxafo: "Señor: Importando más todavía al honor de Vuestra Magestad Imperial que al mio no se crea me he echado fuera del imperio, he determinado quedar algunos días más en esta corte, únicamente para aguardar que se hayan desvanecido los rumores que circulan en el público: y voy a distraerme acabando dos pinturas que tengo principiadas. i Triste de míl Dios es testigo que no aguardaba sino mi despacho de capitán general para ofrecer a Vuestra Magestad una hermosa miniatura de su respatable padre: pero me ha perdido la contestación del ministro de la suerra y, sobre todo, el modo de comunicármela."

En el resto de la carta, como podrá verse, se comprueba lo dicho por Bustamante acerca de las insintaciones de D'Alvimar, para ponerse al servicio de Iturbide, a cuya coronación asistió, ${ }^{2} \mathrm{y}$, además, que mezclada con su ambición política estaba, quizá más importantemente, su deseo de hacer fortuna, para tener "una vejez honrada", para lo cual, dizque trataba de emplear sus fondos en la mina de La Valenciana; con cste pretexto debió ir a Guanajuato y jugándose el todo por el todo, tomar parte en el ataque a San Miguel el Grande, faltando, desde luego, a su palabra de honor, que siempre invocó con falsedad, y a su propia declaración de ser incapaz "de cosas que ni aun pueden caber en mi cabeza".

2 Manuel Romero de Terreros, La corte de Agustin $I$, Emperador de Mttrico. Primera edición publicada por el Museo Nacional de Antropologia, Historia y Ethografia, 1921. 
Tales son las circunstancias que relacionan a D'Alvimar con dos momentos de la historia política de nuestro país, veamos ahora cómo se relaciona con el arte, pues es evidente que muchas cosas cabían en la cabeza del versátil y punto menos que legendario aventurero.

La pintura de la Plaza Mayor de México que ha aparecido en Londres recientemente, con un letrero en el margen inferior que dice "Grande

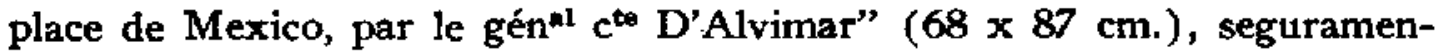
te es una de las dos a que se refiere el general francés en su carta a Iturbide $y$ si en septiembre de 1822 dice tenerlas principiadas, debe haberlas terminado en los meses siguientes, puesto que más tarde pasó a Guanajuato y no debió tener ya tiempo para dedicarse a ese arte; podemos, pues, fecharla con exactitud entre 1822 y 1823 . No parece que la hubiese llevado consigo al ser expulsado de México, ya que la hubieran mencionado, quizá, entre sus pertenencias; sin embargo, es posible que así haya sido $y$ que tal vez enrollada la llevara a Europa para venderla, puesto que sus fondos estaban tan mermados. En cuanto a la otra pintura a que hace referencia, puede haber sido la miniatura del retrato del padre de Iturbide, cuyo paradero es desconocido.

La pintura en cuestión está ejecutada al temple, aplicado con suavidad y transparencia por to que resalta, ante todo, su bien perfilado dibujo. Muestra la Plaza Mayor, vista desde el ángulo sureste, en dirección opuesta al antiguo edificio del Seminario, de manera que luzca, principalmente, la Catedral y el Sagrario; la esquina suroeste del Palacio Nacional sirve de primer término a la composición, y así toda la Plaza se extiende entre éste y la Catedral y el edificio que hoy día es el Monte de Piedad. Continuando al norte la vista del Palacio Nacional, se prolongan las calles que se llamaron del Reloj, hoy avenida República Argentina.

Hay que anotar, desde luego, la importancia en proporción que el pintor dió al cielo, y quizá este razgo seria suficiente indicación de que se trata de una vista de algún artista extranjero, ya que el cielo de México, por su color y transparencia, siempre ha llamado la atención de los visitantes de otros paises. Las perspectivas de los edificios que enmarcan 1a Plaza están bien planteadas, pero falla principalmente en las torres de la Catedral y en algunos otros detalles, por lo cual se descubre que el autor de la pintura era más bien un "aficionado" que un pintor pro- 
fesional; sin embargo, los edificios están bien observados y representados con toda minucia, pero la Catedral no tiene la monumentalidad que le corresponde, ni la silueta de las torres, tan característica, es correcta.

La Plaza Mayor está representada, sin duda, en un día de gala, pues, en primer lugar, está izado el pabellón de las tres garantías, con el águila imperial, al centro de la fachada de Palacio; además, grupos de personas a pie, militares a caballo, puestos y vendimias, se encuentran distribuídos con buen sentido, sin amontonamiento, equilibrando perfectamente la composición. Una comitiva, pasando frente a Catedral y el Sagrario, se dirige a la puerta de honor, la más al sur, del Palacio; precedido por una guardia de caballería, con penachos blancos, va el carruaje imperial, tirado por tres troncos de caballos palomos, y dentro puede verse a un personaje, seguramente Agustín I; otra guardia montada, más numerosa que la anterior, va tras él $y$, al final, otro elegante carruaje. Hacia el centro de la Plaza, a la izquierda del cuadro, hay un bien colocado grupo de peatones, que parecen vitorear al Emperador, enarbolando diversas banderas; otro grupo, esta vez de hombres a caballo, atraen la mirada a un primer plano, a la derecha, y todo está equilibrado por las grandes manchas de sombra, de las cuales puede colegirse que la vista está pintada con luz como de las 10 a las 11 de la mañana. Frente a la Plazuela del Seminario, al costado oriental del Sagrario, una bien alineada batería de artillería está disparando salvas y, por último, en el balcón de Palacio, en primer plano, las damas y militares conversando indican la recepción que tiene lugar en los salones. Las medallones de las portadas de Palacio ostentan, como la bandera izada, el águila imperial.

Por todo 10 anterior no es infundado decir que el autor de la vista quiso representar, ideal y caprichosamente, la Plaza Mayor el día en que Iturbide instituyó la Orden de Guadalupe en la Colegiata, 13 de agosto de 1822 , pues se sabe que fué a la Villa en carroza, ${ }^{3}$ y así la escena se refiere al regreso a Palacio y viene a tener, no sólo un interés artístico sino un aspecto histórico más.

Es de advertir que D'Alvimar no hizo aparecer en la vista de la Plaza Mayor el antiguo edificio del mercado llamado El Parián, seguramente por razones de lucimiento de la Plaza y de la Catedral, así como de composición, mas El Parián estaba entonces todavia en pie, ya que no fué

3 Debo esta noticia y la sugerencia de la circunstancia a que se refiere la vista al señor Manuel Romero de Terreros. 
demolido sino hasta el año de 1843 . Lo anterior tiene antecedente en aquella otra vista grabada por Fabregat (1797) y diseñada por Rafael Ximeno, que muestra el nuevo arreglo de la Plaza ejecutado por Antonio González Velázquez para hacer digno marco a la estatua ecuestre de Carlos IV, obra maestra del ilustre Manuel Tolsá, todo lo cual fué suprimido también, sin duda, por D'Alvimar, haya sido por adulación o por otras causas, para indicar la independencia definitiva de México, pues la estatua no fué trasladada al patio de la Universidad sino hasta el año de $1824^{\circ} \mathrm{y}$ desde el día de la coronación de Iturbide permaneció cubierta hasta su traslado.

El autor de la vista no fué, pues, fiel a la realidad objetiva, sino más bien dispuso su composición de acuerdo con sus intereses artísticos y, seguramente, más que políticos, de conveniencia personal; pero logró un bello conjunto que expresa, ante todo, la visión de un extranjero en un cierto momento histórico y así, esta pintura viene a formar parte de la serie de obras que podría titularse: México visto por artistas extranjeros.

En cuanto al valor artístico, lo más interesante de la pintura de D'Alvimar es el movimiento y la precisión con que sabía dibujar personas, animales y demás detalles de la vida mexicana de principios del siglo xix. Toda la parte inferior del cuadro está deliciosamente dispuesta y dibujados a la perfección todos sus elementos; aquí sí que el pintor y fino observador que era D'Alvimar se ajustó a la realidad escrupulosamente, con la intención de lograr un cuadro costumbrista $y$, en efecto, cumplió su objeto, pues, militares, damas y caballeros, chinacos, clérigos, gente del pueblo, aguadores, vendedores y léperos, no dejan nada que desear en cuanto a propiedad y carácter, así como a corrección y gracia en el dibujo; mas lo verdaderamente admirable es la perfección y variedad de movimientos con que pintó a los caballos y ni qué decir de las vendimias, que agrupan todas las frutas del país, las aguas frescas, las flores y mil otras cosas, hasta gallos garbosos están representados y los perros completan la expresión de vida que el pintor quiso dar. La anatomía de personas $y$ animales es correcta $y$ en algunas figuras, como la de una india con la parte superior del cuerpo desnuda, puede observarse el clasi-

4 Colección de Documentos oficiales relativos a la construcción y demolición del Parián, y a la propiedad reconocida e incontestable que tuvo el Excmo. Ayuntamiento de México en aquel edificio. México, 1843.

5 Fernandez, Justino, El arte moderno en México, 1937. 
cismo del dibujante que, sin duda, tenía escuela, además de una mano muy diestra y de una mirada de escrutinante observador.

Lástima grande que D'Alvimar no pintó más; si en lugar de afanarse por hacer fortuna $y$ andar de buscabullas por estas tierras se hubiera dedicado a pintar los tipos y costumbres del país, en vez de cárceles, molestias y deshonor, hubiera pasado a la historia con un nombre más limpio y habría emulado, quizá, a Linati y a Waldeck; pero el hombre se hizo aventurero y la vista de la Plaza Mayor fué su mejor aventura en México; con ella, si no justifica sus insidiosas visitas a nuestro país, muestra a lo menos, el aspecto más amable de su personalidad y expresa por completo su carácter. No sorprendería ahora descubrir que antes de venir a México D'Alvimar hubiese pintado en Europa escenas de batallas, dibujado modelos de uniformes militares, ilustrado tratados de equitación o cuadernos de modas femeninas, todo es posible de una mano tan hábil $y$ de un temperamento tan inquieto.

La vista de la Plaza Mayor de México por D'Alvimar, pasa a tomar su lugar en la serie de pinturas que representan el sitio en qué se asienta la Catedral y los palacios de los poderes civiles, setie en la que el gran cuadro de la familia Alcázar tiene indiscutible primacía. 


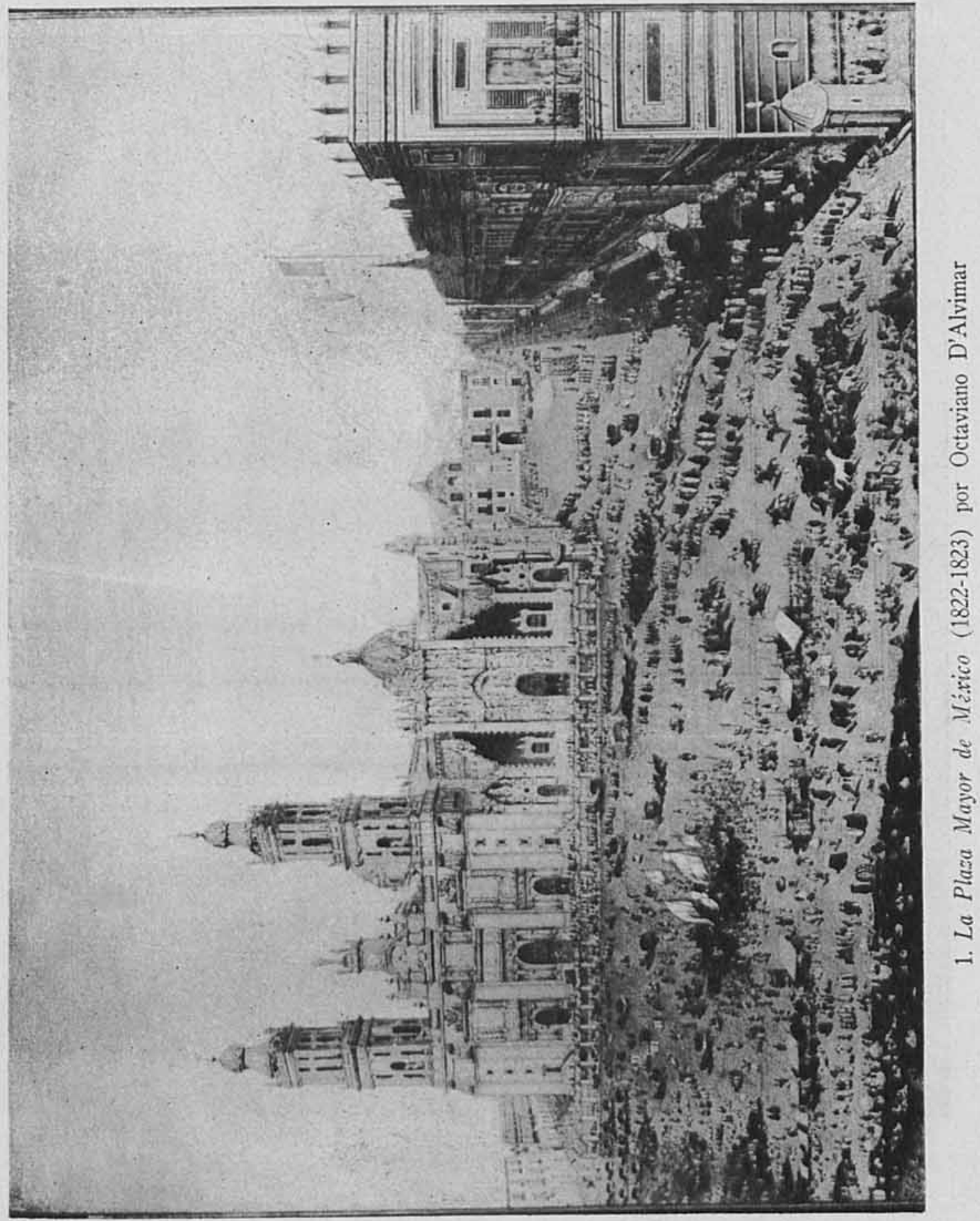




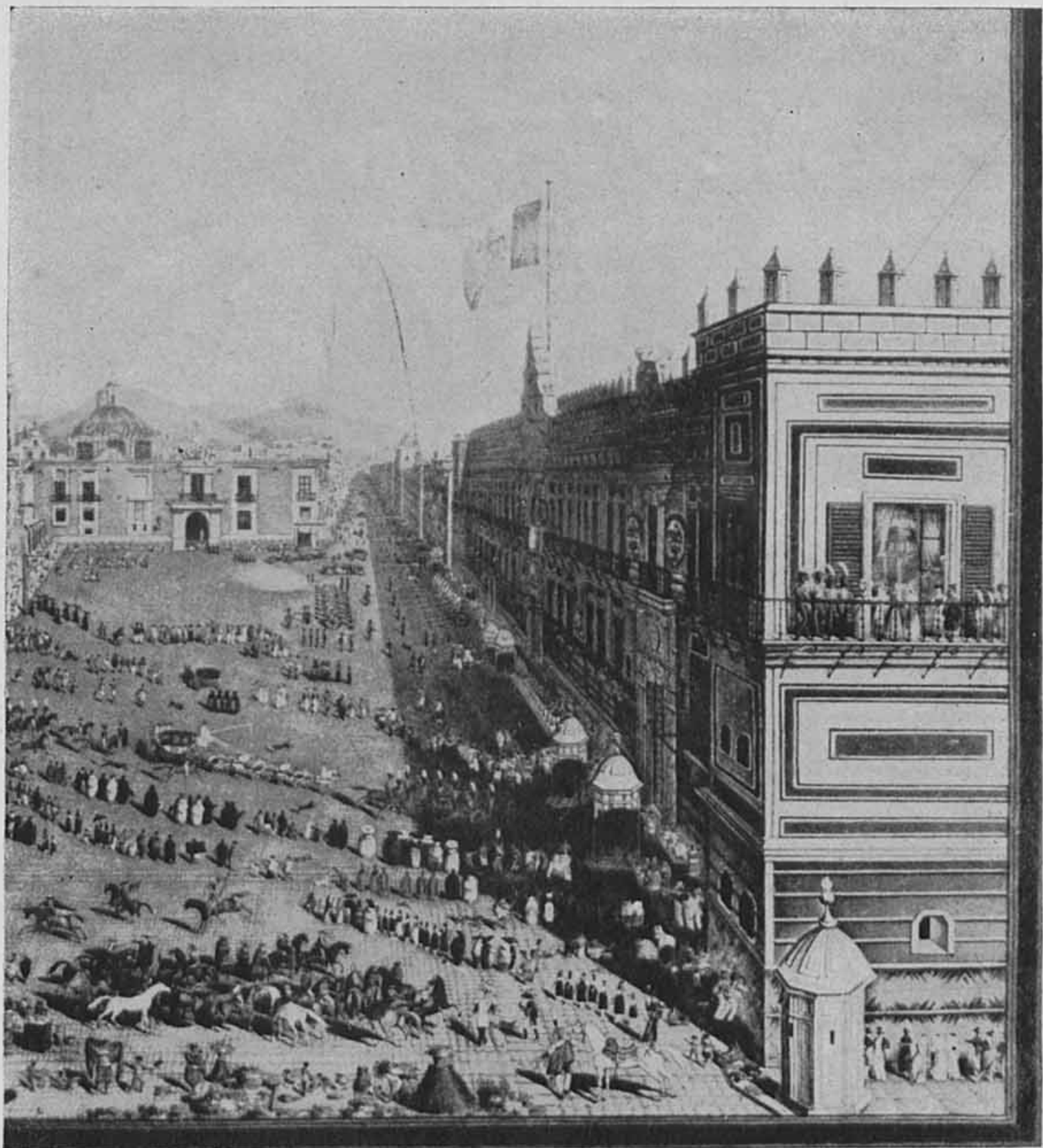

2. Detalle del anterior 


\section{A P E N D I C E \\ CARTA DE D'AlVIMAR A DON AGUSTIN DE ITURBIDE}

Archivo General de la Secretaria de Relaciones Exteriores. Expediente 94-1.

\section{SEÑoR}

Importando más todavía al honor de Vuestra Magestad Imperial que al mio no se crea que me he echado fuera del imperio, he determinado quedar algunos días más en esta corte, únicamente para aguardar que se hayan desvanecido los rumores que circulan en el público: y voy a distraerme acabando dos pinturas que tengo principiadas. ITriste de mil Dios es testigo que no aguardaba sino mi despacho de capitán general para ofrecer a Vuestra Magestad una hermosa miniatura de su respetable padre: pero me ha perdido la contestación del ministro de la guerra, y sobre todo el modo de comunicármela.

Aunque yo no trate a nadie, es regular que más que nunca se desencadene ahora contra mi la calumnia : Sin embargo repito que no sólo no soy acreedor a malos procedimientos, sino que en punto a generosidad me atrevo a decir que nunca cedió D'Alvimar a su padre; y pronto podría probrar a Vuestra Magestad (con cosas que sin duda ignora), que aun respecto de su Augusta Persona he dado pruebas irrefragables de ella desde mi demora en este imperio, el que además voy a dejar sin aun un certificado para poder reclamar en España donde ciertamente no me será muy buena recomendación el haber publicado en las gacetas que yo asisti a la coronación de Vuestra Majestad. No está en mí el impedir que se me calumnie para con Vuestra Majestad: pero doy mi palabra de honor de 
que le he dicho la verdad. Yo deseaba ser capitán general, y sub-jefe de estado mayor en caso de guerra: persuadido a que con el tiempo me grangearía mi buena conducta su benevolencia, y me indemnizaría en parte Vuestra Majestad de lo que he sufrido por este imperio. i Es tan fácil serme útil! Ampáreseme sólo, y déseme seguridad para mi propiedad y persona, tocante a los fondos que deseo emplear para la Mina de La Valenciana, $u$ otras especulaciones no menos importantes en el Sur; y pronto me veré con lo que me es indispensable para tener una vejez honrada, el único objeto de mis deseos.

Habiendo pasado la edad en que los hombres se ponen en las revoluciones, $y$ no pudiendo decirse que soy republicano, ni adicto a cualquier otro partido, sería imposible que Vuestra Majestad sospechase la más minima cosa de mi parte, sin suponerme el peor y más vil monstruo del orbe: pues aunque nunca haya vivido tan mal, lo que de ningún modo es culpa de Vuestra Majestad. El sólo me sostiene desde mi llegada a esta corte. Sería pues mejor clavarme el puñal en el corazón que tacharme de ingratitud. Vuestra Majestad ha tenido cuatro meses mi petición, que habla con la mayor claridad; y confieso cuán cruel me fue la contestación del ministro de la guerra: pero hay mucha diferencia entre que me prohiba el honor sería de otro modo que como eltpitán general, o el sospecharme capaz de cosas que ni aun puetteri caber' en mi cabeza. No oculto cuanto, desde mi natragio sufro por ser reducido a presentarme vestido de paisano pero no significa otra cosa sitho que sufro, y lo evito cuanto puedo. Pidiendo yo mi pasaporte, no se puede decir sino que $D^{\prime}$ Alvimar vino a México, que deseó ser empleado o que se le propuso destino, y que no habiéndoselo \&oncedido, o no habiéndole acomodado volvió a Francia. Esto no ofende a nadie; pues se sabe que en todas tierras hacen sobre este particular 10 que quieren los gobiernos. Pero si se publica que se me ha echado fuera del imperio, no sólo se ataca injustamente mi repstación, sino que se we vulnera en lo más delicado de mi honor: $y$ apelo a la conciencia de Vuestra Majestad para que decida si lo he merecido.

Apenas desvanecidos los rumores que circulan acerca de mi partida, téndré el honor de wisar a Vrentra Majestad del día que me pondré en canino para ver por mi mismo la min de La Valenciana; y me tomare la libertad de escribir a Vuestra Majestad de Guanajuato. Si es una especulición que proyecto, me embarcaré luego en el puerto más vecino para Nueva-Orleans; pues conoce mejor qive nadie Vuestra Majestad ol triste estado de mis facultades pecuniarias: pero hallando allá cónsules 
de mi nación sin hablar de lo que les impone su deber, siempre se harán un placer de servirme hasta Francia. Si acaso se digna Vuestra Majestad echar una mirada benévola sobre mí durante mi viaje, $y$ acordarse de todo lo que he padecido por este imperio, obedeceré muy gustoso a sus órdenes, es decir que volveré a esta corte con el mismo corazón, con el mismo zelo y deseo de agradar, sin descontento, sin rencor alguno (pues no le tienen los Franceses) : y si no encuentra en mi un amigo, porque exige la amistad igualdad de condiciones, y reciprocidad de servicios, lo que no puede existir entre el superior y el inferior; ( $y$ repito que todas las minorías que han buscado amigos han hallado intrigantes que los han perdido): si no encuentra en mi Vuestra Majestad un amigo, repito, me atrevo a decir que el menos tendrá un leal y fiel vasallo.

SEÑoR,

A los pies de Vuestra Majestad Imperial su humilde, respetuoso servidor ( $y$ vasallo de corazón), que, como este imperio ha menester, ruega fervorozamente a Dios prospere su importante vida dilatados años. México y septiembre 20 de 1822.

Rúbrica (Octaviano D'Alvimar.)

(Se respetó la ortografía.)

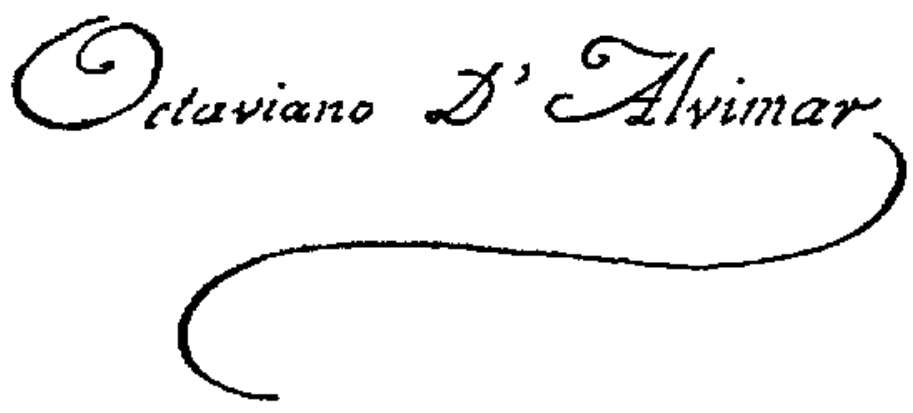

